\title{
DESARROLLO a la ecuatoriana
}

\section{Yolanda Alfaro}

Este artículo presenta una revisión de los principales aspectos económicos, sociales y politicos que han dado lugar a la implementación de un nuevo modelo de desarrollo alternativo en Ecuador, y con ello aporta elementos para comprender por qué Ecuador, a partir de los cambios promovidos por el gobierno de la Revolución Ciudadana, se encuentra frente a una nueva fase, inscrita en un modelo de desarrollo alternativo denominado buen vivir.

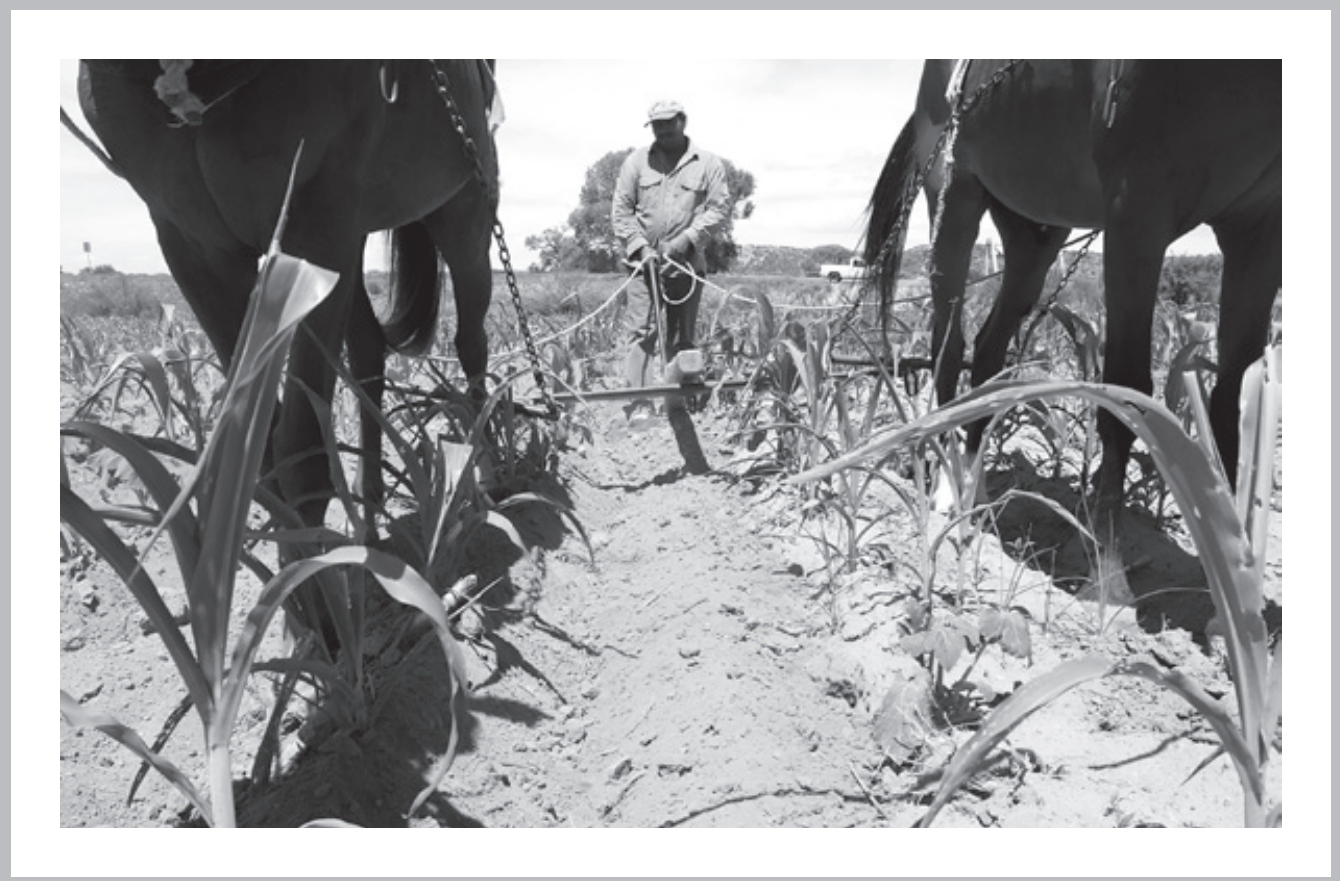

INTRODUCCIÓN

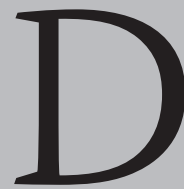

espués de sucesivos episodios de inestabilidad política y de crisis económica, Ecuador ha conseguido redireccionar los principios rectores de su desarrollo hacia una visión alternativa: el buen vivir. Para el campo de los estudios críticos del desarrollo, el modelo del buen vivir no sólo constituye la oportunidad de recapitular las temáticas asociadas al desarrollo como proyecto y como proceso, sino que puede ser un instrumento para reorientar la discusión de la teoría y la práctica del desarrollo hacia la construcción de alternativas para el cambio social. En este artículo se presentarán los principales aspectos de 
la historia económica ecuatoriana para identificar el surgimiento del buen vivir como un modelo de desarrollo alternativo dentro del marco de la economía-mundo capitalista, y con ello aportar elementos para la discusión teórica y práctica de los procesos de cambio social y desarrollo en América Latina.

\section{LA VIEJA ESTRUCTURA DE DESARROLLO}

La estructura económica de Ecuador ha pasado por cuatro fases después de su independencia: los rezagos coloniales; la modalidad primario-exportadora; la industrialización por sustitución de importaciones, y el ajuste neoliberal. Históricamente, cada una de esas modalidades ha estado relacionada con procesos políticos específicos, con alianzas hegemónicas de los grupos dominantes, con una estructura peculiar de Estado y con configuraciones especiales de política económica en el ámbito internacional. ${ }^{1}$ Cada una de estas fases se ha superpuesto a la otra a través de factores de orden externo, como son las modificaciones del capitalismo a nivel mundial, y las dinámicas sociopolíticas internas.

A partir de la separación de España, la economía ecuatoriana, en esta primera fase, se incorporó a la reproducción internacional del capital mediante la exportación de productos primarios. El modelo primario exportador (MPE) en Ecuador, que empezó como tal a partir de 1954, fue un esfuerzo subordinado a la lógica del capital externo mediante la producción de cacao, ya que dependía de la demanda de los países del centro. ${ }^{2}$ Los principios del MPE afianzaron el carácter dependiente que le habían dejado los diversos intereses mercantiles y financieros del poder económico colonial y las élites que dirigieron el sistema hacendal. Por lo tanto, la estructura económica alcanzó insignificantes variaciones en lo que respecta al campo económico respecto a la fase de la Colonia.

La segunda fase, de los años sesenta y setenta, fueron un periodo de cambios estructurales debido al papel activo que tomó el Estado a través de las regulaciones del mercado, las inversiones públicas, las políticas de redistribución de los ingresos y el nacionalismo económico. ${ }^{3}$ Las medidas económicas aplicadas en estos años derivaban de la alianza entre empresarios industriales y la burocracia, que estaba orientada a fortalecer un Estado desarrollista, procurando enfrentar los desequilibrios externos, mientras se buscaba una reintegración del país al mercado mundial. La aplicación de las diversas políticas económicas del Estado desarrollista dio un giro más sustancial a mediados de los años setenta, cuando el petróleo apareció en la escena económica. Ecuador entró de lleno en el mercado mundial a través del potencial hidrocarburífero. Se convirtió en la estrategia económica más importante de negociaciones a nivel internacional debido al interés de los consorcios transnacionales que empezaron a buscar otras alternativas de suministro a nivel mun- dial. ${ }^{4}$ No obstante, la política de sustitución de importaciones, que cruzaba todo el escenario latinoamericano con proyectos de industrialización nacional, fue una medida económica truncada en el caso ecuatoriano.

No logró transformar dinámicamente el mercado interno, no alcanzó una redistribución productiva, no garantizó el flujo adecuado de capitales para la readecuación del aparato productivo superando su heterogeneidad estructural, no pudo generar una real concentración de esfuerzos privados y estatales para crear la infraestructura necesaria y tampoco se diseñó - mucho menos aplicó- una verdadera política arancelaria que hubiera protegido activamente a la naciente industria hasta que ésta alcanzara niveles prudentes de competitividad internacional. ${ }^{5}$

La imposibilidad de impulsar la industrialización a partir de una estrategia de desarrollo hacia adentro, y así superar el patrón tradicional de la acumulación primario-exportadora, profundizaron aún más las desigualdades sociales y regionales. La estructura productiva y la estructura social se hicieron más heterogéneas, desatando masivas migraciones campo-ciudad, subempleo urbano y economía informal. ${ }^{6} \mathrm{Al}$ igual que en otras partes de América Latina, el gobierno optó por la aplicación de las recetas del Consenso de Washington. En 1984, el entonces presidente, León Febres Cordero, abrió las puertas del país a la ideología neoliberal y con ello a los ajustes estructurales, basados en una economía abierta y desregularizada. Para conseguir una nueva modalidad de acumulación primario-exportadora moderna - apertura de mercados de importación para los productos de los países desarrollados y exportación de productos agrícolas y minerales a precios bajos - la primera acción fue el desmantelamiento del Estado, sobre todo en lo que concernía a sus funciones reguladoras en el proceso nacional de desarrollo.? 
A finales del siglo xx, Ecuador había acordado la renegociación de la deuda con los acreedores internacionales en base en las condicionalidades del capital financiero internacional, lo cual provocó una de las peores crisis económicas de su historia. ${ }^{8}$

\section{Punto DE INFLEXión}

Con la llegada del nuevo milenio, la economía ecuatoriana dio su último giro hacia el cumplimiento de las condicionantes impuestas por el Fondo Monetario Internacional (FMI) para el pago de la deuda externa mediante la liberalización de los mercados internos, apertura externa de la economía, privatizaciones y flexibilización laboral, políticas sociales focalizadas y concesiones de los servicios públicos, autonomía del poder judicial y descentralización. No obstante, el punto más drástico fue el Feriado Bancario: una medida que el gobierno ejecutó con el objetivo de instaurar oficialmente un esquema de dolarización de la economía en pos de aplicar un salvataje a la crisis financiera, que la alianza entre la élite gobernante y los banqueros había subsumido. ${ }^{9}$ Así, a partir del 9 de enero de 2000, se adoptó como medida la imposición de un esquema de dolarización oficial de la economía.

El retiro del Estado de la regularización financiera fue el punto culminante del neoliberalismo, pero al mismo tiempo fue su punto de inflexión, porque a partir de las consecuencias del neoliberalismo -inflación, devaluación, recesión, quiebra de empresas, desempleo y la mayor ola migratoria de la historia- se articularon las fuerzas sociales en torno a la búsqueda de un nuevo proyecto político y de desarrollo que tuviese como base la participación ciudadana, el manejo honesto de lo público, la mayor garantía de derechos y la transformación del modelo neoliberal.

Tras un nuevo periodo de elecciones presidenciales, Rafael Correa, con su propuesta de un nuevo proyecto político y económico denominado Revolución Ciudadana, promueve la reconstitución del país a través de la una nueva Constitución. En este proyecto convergieron varias de las fuerzas sociales de Ecuador: movimiento indígena, agrupaciones campesinas y sindicales, capas medias e intelectuales identificadas con la izquierda. En 2008, Ecuador se promulga como un Estado plurinacional e intercultural, con un nuevo régimen de desarrollo basado en principios de derechos. ${ }^{10}$

\section{El Buen Vivir: el nuevo modelo del desarRollo}

El nuevo sistema económico de Ecuador se define por las formas de organización económica pública, privada, mixta, popular y solidaria, que incluye los sectores cooperativistas, asociativos y comunitarios. Los principios de esta nueva base económica se materializaron en el Plan Nacional para el Buen Vivir 2007-2011. Se trata de un plan que, por primera vez en la historia ecuatoriana, apuntaba hacia formas alternativas de desarrollo mediante la redefinición de la economía como el «instrumento» para la realización del bienestar real de los seres humanos y la garantía de los derechos de la naturaleza.

Las primeras medidas fueron la construcción de una agenda de políticas posneoliberales en la que la piedra angular fue la recuperación del Estado y sus instituciones, es decir, la planificación de la política social, la regulación económica, el control y la redistribución de la riqueza y la soberanía nacional; así como el diseño de una política económica que tenga como base la participación ciudadana y la garantía de derechos.

A partir de la definición estratégica de estos dos puntos, que condensan la tónica del cambio del enfoque de problemas estructurales de Ecuador, es posible señalar que el nuevo modelo de desarrollo es de carácter alternativo, porque busca una forma de desarrollo más participativa, socialmente inclusiva y con vinculación soberana al sistema mundo. Pero más que hacer una definición de lo que es un modelo de desarrollo alternativo, es necesario preguntarse ¿cuáles son los aspectos con los que se puede reconocer el buen vivir como una perspectiva alternativa de desarrollo?

El desarrollo alternativo, sea como resistencia a la globalización neoliberal o como apuesta de sociedad diferente, se adscribe a los estudios críticos del desarrollo en relación a los enfoques del otro desarrollo. Tal como señalan Veltmeyer y Parpart, ${ }^{11}$ la alternativa se destaca por criticar la lógica del desarrollo «de arriba hacia abajo». En ese entendido, la noción del buen vivir se adscribe como concepto y práctica alternativa al desarrollo a través de la corriente crítica posestructuralista y posmodernista que cuestiona las formas de exclusión estructural, en particular la exclusión de los conocimientos, las voces y las preocupaciones de quienes, paradójicamente, deberían beneficiarse del desarrollo. ${ }^{12}$

De acuerdo a Santos, ${ }^{13}$ un enfoque de desarrollo alternativo se sustenta en la rup- 
tura epistemológica y sociopolítica del paradigma de la modernidad. Si bien es cierto que el principio epistémico del buen vivir es la pluralidad de formas de conocimiento y la transición hacia el reconocimiento como un nuevo paradigma de organización social de formas emergentes de organización, es necesario distinguir las dos dimensiones que presenta: la dimensión de la experiencia y la práctica y la dimensión ético-política. ${ }^{14}$

Desde la dimensión de la experiencia y la práctica, aparece como un proyecto político de cambio en la Región Andina, específicamente en Ecuador y Bolivia. Ambos países incluyeron en la formulación de sus recientes constituciones (2008 y 2009, respectivamente) el buen vivir o vivir bien como un paradigma de cambio alternativo, tratando así de dar respuesta a la profunda crisis de hegemonía que detonó a 
finales del siglo xx. Ambas formas de proponer un proyecto político alternativo tienen en común la recuperación de la cosmovisión de los pueblos y nacionalidades indígenas para construir una sociedad que reconozca la convivencia del ser humano en diversidad y armonía con la naturaleza, como condición y presupuesto de ordenamiento político, económico, social y cultural. ${ }^{15}$

El modelo del buen vivir aparece en la constitución como un concepto que integra el devenir de la vida económica, política, social y cultural. Tal como lo definen Falconí y Munóz, «[...] es una forma de concebir el desarrollo desde otro punto de vista. Es un sentido histórico que interviene la dirección planteada por el Consenso de Washington y su lisa ad hoc de singulares instituciones, dinámicas sociales y patrones culturales». ${ }^{16}$

Uno de los aspectos que más llama la atención, y que se presenta bajo la consigna «Régimen del Buen Vivir», tiene como base el reconocimiento de un conjunto de derechos nuevos; por ejemplo, aquéllos que están referidos a personas y grupos de atención prioritaria, comunidades, pueblos y nacionalidades, participación, libertad, de la naturaleza y protección. ${ }^{17}$

En ese sentido, los principios que definen al buen vivir de Ecuador como un modelo de desarrollo alternativo son: 1) repensar el desarrollo por fuera de la mirada lineal y unidireccional que trajo consigo la modernidad occidental; 2) recuperar la perspectiva espiral del tiempo en la que el ser humano es una pieza más del todo — realidad-, por lo tanto, es un planteamiento que abandona la visión antropocentrista que ha primado en el desarrollo occidental, ${ }^{18}$ 3) reconceptualizar la noción de calidad de vida o de bienestar a través del reconocimiento de formas que no dependen solamente de la posesión de bienes materiales, ni de acceso a servicios o de los niveles de ingreso medidos por el producto interno bruto (PIB), ${ }^{19}$ y 4) reconocer otros derechos, libertades, conocimientos oportunidades y potencialidades de los seres humanos, comunidades, pueblos y nacionalidades. ${ }^{20}$
Este acercamiento teórico demuestra que la noción de buen vivir que propone Ecuador presenta diferencias en cuanto a los objetivos que persigue: encarar la naturaleza del desarrollo mediante de la deconstrucción del discurso de desarrollo occidental, considerando que el crecimiento no es una finalidad netamente cuantitativa, sino un proceso cualitativo que integra la naturaleza y la comunidad.

A diferencia del modelo de sustitución de importaciones, que pretendía la construcción de un proyecto de desarrollo en base a la autodeterminación nacional, el buen vivir está planteado como un desarrollo alternativo, como una nueva vía política de cambio y transformación de la visión de desarrollo centrada en la participación y la equidad. Esta dimensión ético-política plantea la (re) construcción de un sistema económico y político mediante la recuperación de la condición colectiva de la producción y la reproducción de la vida. ${ }^{21}$

Otro tópico que revela el potencial explicativo del buen vivir es el referente a la economía social y comunitaria, donde la forma comunidad se opone a la forma valor poniendo en escena la complementariedad y reciprocidad, además de la redistribución y la dualidad de los procesos inherentes a la producción, reproducción y consumos materiales y simbólicos. La matriz económica desde los principios del buen vivir comprende la integralidad de las estructuras, las instituciones, las normas y los procedimientos propios de las comunidades ancestrales. ${ }^{22}$

\section{Conclusiones}

El modelo teórico de desarrollo de Ecuador puede considerarse como alternativo puesto que ha abierto la posibilidad de un cambio epistemológico respecto a la concepción tradicional del desarrollo y la institucionalidad del sistema capitalista neoliberal de acumulación y (re)distribución. No obstante, y a pesar de los avances que ha podido alcanzar el buen vivir como propuesta alternativa al desarrollo, sobre todo en lo que concierne al ámbito discursivo, todavía constituye un campo teórico muy amplio y diverso, lleno de encuentros y desencuentros.

En la última década, Ecuador ha pasado de procesos políticos fallidos a una dinámica reformista y modernizadora con éxito indiscutible en los aspectos sociales; sin embargo, el proceso de las reformas económicas todavía tiene limitaciones. Quizá la más importante, por el reto que representa, es que la matriz productiva no se ha modificado; Ecuador sigue siendo un país esencialmente primario-exportador. Es por ello que queda abierto el análisis crítico de las políticas del buen vivir. Resta una evaluación profunda al desempeño gubernamental de la Revolución Ciudadana y la implementación de las políticas del Plan Nacional del Buen Vivir 2007-2010, puesto que los puntos más críticos se encuentran en el campo político, es decir, 
justo en los intersticios que se han generado a partir de la adopción de una política de carácter posneoliberal.

Al desmontar los principios de la estructura económica neoliberal se tuvo que reconfigurar el papel del Estado, lo cual implicó el posicionamiento de un régimen soberano de gobierno. Las presiones externas actualmente tienen menos peso político, lo cual ha permitido que la presencia del Estado se presente como un actor social de cambio a través de inversión pública y programas sociales. Éste es, quizá, el indicador cualitativo más importante para demostrar que Ecuador se encuentra transitando por un proceso de cambio social, y que el buen vivir constituye el medio, pero también el fin, para transitar hacia esa una nueva estructura económica.

\section{Notas}

1 Alberto Acosta, Breve historia económica de Ecuador, Quito, Corporación Editora Nacional, 2001.

2 Mora Enrique Ayala, Resumen de Historia del Ecuador, Quito, Corporación Editora Nacional, 1993.

3 Juan Paz y Miño Cepeda, «El gobierno de la revolución ciudadana: una visión histórica», en S. Mantilla y Mejía Santigo (coordinadores), Balance de la Revolución Ciudadana, Quito, CELAP- Editorial Planeta del Ecuador, 2012.

4 Entre 1973 a 1980, época del auge petrolero, Ecuador registró un crecimiento per cápita de 3.3\%, el mayor en todo el siglo xx; superior al promedio del grupo de países de América Latina y al de Estados Unidos, que alcanzó 1.0\% (Hofman, citado en Alberto Acosta, Breve historia económica de Ecuador, p. 127).

5 Alberto Acosta, op. cit., p. 16.

6 Carlos Larrea, «La estructura social ecuatoriana entre 1960 y 1979», Nueva Historia del Ecuador, vol. 11, Quito, Corporación Editora Nacional, 1990.

7 Alberto Acosta, op. cit.

8 «La caída del PIB real para 1999 fue de 7.3\% medida en sucres y de más de 30\% en dólares [...] La política económica en 1999 provocó una devaluación de 216\%, una inflación de 52\%, una caída del salario real de $23 \%$ y una salida de capitales privados de 15\% del PIB» (Alberto Acosta, op. cit., p. 195).

9 El presidente Sixto Durán, en 1994, creó la Ley de Instituciones Financieras que liberalizó las tasas de interés y permitió la libre circulación de capitales y el aumento de los créditos; esto provocó que cuatro años después se declarará un feriado bancario de 24 horas, que finalmente duró cinco días. Todas las operaciones financieras estaban suspendidas y bajo un decreto de congelamiento de depósitos todas las cuentas de más de dos millones de sucres quedaron paralizadas.

10 Capítulo cuarto, artículo 283. El sistema económico es social y solidario; reconoce al ser humano como sujeto y fin; propende a una relación dinámica y equilibrada entre sociedad, Estado y mercado, en armonía con la naturaleza; y tiene por objetivo garantizar la producción y reproducción de las condiciones materiales e inmateriales que posibiliten el buen vivir.
Fander Falconí y Pabel Muñoz, «Ecuador: de la receta del "Consenso de Washington” al posneoliberalismo» en S. Mantilla y Mejía Santiago (coordinadores), Balance de la Revolución Ciudadana, Quito, CELAP, Editorial Planeta del Ecuador, 2012.

11 Veltmeyer y Parpart, «La evolución de una idea: estudios críticos del desarrollo» en Henry Veltmeyer (coordinador), Herramientas para el cambio: Manual para los estudios críticos del desarrollo, La Paz, Cides, UMSA, OXFAM, 2011.

12 Arturo Escobar, «El "posdesarrollo" como concepto y práctica social» en Daniel Mato (coordinador), Políticas de economía, ambiente y sociedad en tiempos de globalización, Caracas, Facultad de Ciencias Económicas y Sociales, Universidad Central de Venezuela, 2005.

13 Boaventura de Sousa Santos, «La difícil construcción de la pluralidad» en Los nuevos retos de la América Latina. Socialismo y Sumaj Kawsay, Quito, SEnPLAdes, 2010.

14 Raúl Prada, «El vivir bien como alternativa civilizatoria: Modelo de Estado y modelo económico», en Grupo Permanente de Trabajo sobre Alternativas al Desarrollo, Más Allá del Desarrollo, Quito, Fundación Rosa Luxemburgo-Abya Yala, 2011.

15 Eduardo Gudynas y Alberto Acosta, «El buen vivir o la disolución de la idea del progreso», en La línea de fuego, mayo 25, 2011.

16 Fander Falconí y Pabel Muñoz, op. cit., p. 94.

17 René Ramírez Gallegos, «Izquierda y "buen capitalismo". Un aporte crítico desde América Latina», Nueva Sociedad, núm. 237, 2012; Gudynas, op. cit.

18 Ana María Larrea, «La disputa de sentidos por el Buen Vivir como proceso contra hegemónico», en Los nuevos retos de la América Latina. Socialismo y Sumaj Kawsay, Quito, SENPlADES, 2010.

19 Ramírez, op. cit.

20 Eduardo Gudynas, «Buen vivir: Germinando alternativas al desarrollo», América Latina en movimiento, Quito, número 462, ALA, febrero 2011.

21 Gudynas op. cit.; Ramírez, op. cit.

22 Raúl Prada, op. cit. 